\title{
Research Progress in Tobacco Fermentation
}

\author{
Yang Yang1*, Qianrong Peng1, Mingyi Ou1, Youxiang Wu1', Jing Fang² \\ ${ }^{1}$ Technical Center, China Tobacco Guizhou Industrial Co., Ltd., Guiyang, China \\ ${ }^{2}$ China Tobacco Guizhou Industrial Co., Ltd., Guiyang, China \\ Email:*470503299@qq.com
}

How to cite this paper: Yang, Y., Peng, Q.R., Ou, M.Y., Wu, Y.X. and Fang, J. (2018) Research Progress in Tobacco Fermentation. Journal of Biosciences and $\mathrm{Me}$ dicines, 6, 105-114. https://doi.org/10.4236/jbm.2018.66008

Received: May 29, 2018

Accepted: June 25, 2018

Published: June 28, 2018

Copyright @ 2018 by authors and Scientific Research Publishing Inc. This work is licensed under the Creative Commons Attribution International License (CC BY 4.0).

http://creativecommons.org/licenses/by/4.0/

\begin{abstract}
Flue-cured tobacco fermentation is one of the important processes in cigarette manufacturing production. In this thesis, the author interviewed the flue-cured tobacco fermentation mechanism, quality changes of fermentation process, environmental influences on fermentation quality, and fermentation method. By aiming at shortcomings of the current study, the author proposed the near-infrared means to judge the best period of fermentation and provided reference for cigarette enterprises.
\end{abstract}

\section{Keywords}

Tobacco, Fermentation, Near Infrared Spectroscopy, Research Progress

\section{Introduction}

Flue-cured tobacco fermentation is the important process in flue-cured tobacco fermentation process. Unleavened new cigarette has multiple quality defects, such as offensive odor, simulative extrusion, no fragrance of former smoke, monotonous smoking aroma quality, insufficient fragrance, no direct utilization in cigarette production [1] [2]. Fermentation can improve more offensive odor and insufficiently mellow smell, so as to improve tobacco quality [3]. At present, the relevant study on fermentation is mainly concentrated on four aspects: fermentation mechanism study, change quality study on tobacco fermentation process, relevant study of tobacco fermentation environment on quality influences, and tobacco fermentation method study.

\section{The Study on Tobacco Fermentation Mechanism}

\subsection{Theory of Oxidation}

In 1867, two Soviet Union scholars proposed the theory. They thought that organic substances take place oxidation with oxygen in air under the catalytic ac- 
tion of inorganic elements (Fe, Mgetc), resulting in changes of chemical substances in tobacco. The existing studies also support the theory of oxidation. The findings show that [4], under the aerobic conditions, transformation speed of chemical substances in the tobacco is faster than anaerobic conditions. Adding oxidizing agent ethylene oxide can speed up the fermentation progress of tobacco, while airtight oxygen reduction restrains enzymatic browning reaction of tobacco, so as to slow down speed to darken tobacco color.

\subsection{Theory of Microbial Action}

In 1980s, Junior Leif of the Soviet Union indicated that the initial cause for tobacco fermentation is that microorganisms participate in the fermentation activity and follow-up process is conducted under the action of inorganic catalyst. Based on it, he proposed the theory of microbial action [5]. The existing studies find that [4] [6] microorganisms in domestic redried strips mainly include bacteria, mould and actinomyces. Bacteria occupy most of them, while mould and actinomyces are minorities. Yeast is little or can't be detected at all. When Di Giacomo et al. [7] did a fermentation study on Italian flue-cured tobacco, bacteria, yeast and a few lactic acid bacteria were separated. Wu Xueying et al. [8] used 16SrRNA cone library sequencing method to analyze dominant bacteria in fermentation tobacco in Qujing tobacco-growing area, finding that the dominant bacteria of bacteria include enterobacteriaceae, pseudomonas and flavobacterium. By deeply studying physiological properties of microorganisms in fermentation tobacco, it can be found that some microorganism strains have the role of reducing nicotine, Tabacco-specific Nitrosamines, proteins and cellulose contents and improving fragrance [9]-[14].

\subsection{Theory of Enzymatic Action}

Enzymatic theory of tobacco fermentation was proposed by Leif. In his opinions, tabocco fermentation is caused by oxidase contained in tobacco, including oxidase, catalase, and peroxidase. The existing studies find that polyphenol oxidase and peroxidase activity in fermentation process are present in the tendency of firstly rising and then reducing [15]. The activity of lipoxygenase, $\alpha$-amylase, protease, cellulase and sucrose is on a declining curve. Enzymatic activity stored in high-temperature and high-wet areas has the higher enzymatic activity. Adding enzymic preparation in tobacco can promote the improvement of tobacco quality [16].

\section{The Quality Change Study on Tobacco Fermentation Process}

\subsection{Changes in Appearance Quality and Physical Properties of Tobacco Fermentation Process}

The existing studies show that [17]-[22] in the entire fermentation process, dried strips' colors are gradually darkened from orange to deep orange, reddish brown 
and brown. The uniformity and saturability of redried strips gradually get better in early stage of fermentation and become worse after reaching the optimum. The brightness is gradually darkening. Oil content is increased in early stage of fermentation and then it is reduced after reaching maximum. Tobacco structure tends to be loose with the extension of fermentation time. Changes of appearance quality take place top 18 months of natural fermentation, while equilibrium moisture content is on a declining curve.

\subsection{Changes of Chemical Compositions in Tobacco Fermentation Process}

Furthermore, the existing studies also indicate that with the increase of the organic acid content in fermentation process, $\mathrm{pH}$ value is present in the down trend [23] [24] [25]. Total sugar and reducing sugar contents are reduced. It has the fastest speed in $6-12$ months of fermentation. The falling range under the different warehouse environments has the significant difference [26]. The statement on total nitrogen content is inconsistent. Partial scholars indicate that it is present in the down trend of the small amplitude [25] [27], while other scholars indicate that the changes are not obvious [28]. The alkaloid change is weak [22] [25] [26] [27]. Petroleum ether extract and plamochromicpigment (chlorophyll and carotenoid) take place a great change, thus tobacco's fragrance gets better and fragrance is mellow [29] [30] [31] [32]. Srivastava et al. [33] found that polyphenols of tobacco in fermentation process take place oxidative degradation and turn into aroma substances and brown pigment. Among which, chlorogenic acid has the biggest falling range, reaching $50 \%$. Rutin content basically maintains unchanged or it is slightly reduced.

\subsection{Sensory Quality Changes in Tobacco Fermentation Process}

In fermentation process, sensory quality gradually gets better and it is basically stable and then it is reduced [17] [34] [35].

\section{Relevant Study on Influences of Tobacco Fermentation Environment on Quality}

Fermentation environment is the important factor in fermentation process. Temperature, humidity and air are key factors. Different warehouses have diverse properties and tobacco fermentation effects are also diverse. The findings indicate that [36] [37] [38]: the strips stored under the higher environmental temperature $\left(>25^{\circ} \mathrm{C}\right)$ and relatively suitable relative humidity $(55 \%-65 \%)$ have the better appearance quality and it is good for improving strip quality; when warehouse environment's relative humidity is greater than $65 \%$, it is not good for tobacco fermentation. Firstly, tobacco appearance quality is poor. Secondly, tobacco is easy to take place mould. In temperature and humidity management process, constant temperature of lower relative humidity should be maintained. As improving mould proof, it is better to reduce humidity, instead of lowering 
temperature at random. This is economic, scientific and reasonable and conforms to tobacco maintenance requirements.

Predecessors studied the warehouse construction and equipment study [39]-[50]. Some of them attempted to use the air-conditioning unit intelligent control system, computer temperature and humidity measurement control system, tobacco warehouse temperature and humidity monitoring system of multi-sensor data fusion, temperature and humidity detection system of wireless communication technique, different ventilation drying dehumidification system, fully integrated automation system, air cooled heat pump water chilling unit+ combined air-conditioning unit dehumidification temperature control system, condensation heat recycling heat pump dehumidification system and liquid desiccant system, mechanical regulation warehouse environment method, controlled atmosphere storage technology and nitrogenization oxygen consumption seal technology to regulate fermentation temperature and humidity. Other scholars attempted to utilize solar thermal energy to accelerate tobacco fermentation speed, thus temperature is controlled in the suitable range. One-year fermentation is equal to three-year effect of natural fermentation. HVAC technology fumigates and kills insects of tobacco fermentation. The phosphine exhaust purification treatment system and air-conditioning system conduct optimal design to realize zero release of harmful gas.

\section{The Study on Tobacco Fermentation}

The fermentation method on tobacco is mainly concentrated on accelerating fermentation and restraining fermentation.

The main study on accelerating fermentation is shown as follows [51]-[57]: through warming and humidification, the artificial fermentation method is used to reduce tobacco fermentation time. Exogenous beneficial microorganisms can coordinate with and improve chemical compositions of aging tobacco, improve tobacco fragrance, and shorten aging period of tobacco. After adding enzymic preparation, tobacco fermentation is accelerated.

The main study on restraining fermentation is shown as follows [58]-[68]: sealing oxygen-consumed storage can restrain tobacco fermentation speed; after pumping nitrogen or vacuumizing during the fermentation period can prevent from tobacco mould and lengthen the best fermentation period of tobacco with proper fermentation. Nitrogen in later period of mechanical regulation method with low emission can restrain excessive fermentation of tobacco and relatively lengthen the best utilization period of tobacco. Controlled atmosphere storage lengthens the time for the best fermentation quality for strips relative to the natural fermentation.

\section{Discussion}

At present, the domestic and overseas scholars conduct lots of studies on the fermentation, but they have shortcomings in individual aspects. As a cigarette 
company, we urgently need to know the optimum fermentation time of flue-cured tobacco. But so far, no one or any studies have shown how to determine the optimal fermentation time for flue-cured tobacco. Most companies still rely on sensory quality reviews. This is obviously not very scientific. The best fermentation period of tobacco is the best period for tobacco to enter into formula utilization. The industrial judgment method on the best fermentation period of tobacco still gives priority to sensory evaluation [17] [19] [69]. Sensory evaluation is easy to be affected by artificial subjective influences. The accuracy and reproducibility are weaknesses. It is urgent to use a chemical detection means to do auxiliary judgment on the best fermentation period of tobacco.

The NIR (Near Infrared Spectrum) is advantaged with fast analysis, simple sample pretreatment, high analysis efficiency, wide sampling range, and suitable for lossless online monitoring, so it is widely used in food [70] [71] [72], tobacco [73] [74] [75] [76], petrochemical engineering [77], qualitative and quantitative analysis of medicine [78] [79] [80] or other fields. At present, China Tobacco Guizhou Industrial Co., Ltd. has established the technical networked united lab of NIR. With Speicher portable NIR instrument, NIR analysis detection technology is used to do qualitative and quantitative analysis on the best fermentation period of tobacco. In the future, the instrument will be carried to each warehouse to judge the best fermentation period of tobacco. Therefore, we suggest that cigarette industry enterprises consider using NIR to determine the optimal alcoholization period of tobacco leaf in future research.

\section{Acknowledgements}

The study was funded by China Tobacco Guizhou Industrial Co., Ltd. (QYGJ [2017] 19, Study on fast detection method of tobacco fermentation, GZZY/KJ/ JS/2017DY004-1). The author wants to thank the Colleague of the Technical Center of China Tobacco Guizhou Industry Co. Ltd. They have given a lot of help to research ideas.

\section{References}

[1] Gong, C.R. (1993) Preliminary Working of Tobacco Raw Materials. China Light Industry Press, Beijing, 183-184.

[2] Wang, R.X. (2003) Tobacco Chemistry. China Agriculture Press, Beijing, 175.

[3] Yan, K.L., Wu, Y., Zeng, X.Y., et al. (2011) The Research Progress on Tobacco Fermentation Technology Based on Improving Quality and Reducing Harms. Hubei Agricultural Sciences, 50, 451-453.

[4] Zhu, D.H., Chen, R., Chen, Z.G., et al. (2001) The Microorganism Changes between Natural Fermentation and Artificial Fermentation Process of Tobacco and the Study on Enzymatic Activity Relationship. Journal of China Tobacco, 7, 26-30.

[5] Jin, W.B. and Dai, Y. (1994) Tobacco Chemistry. Tsinghua University Press, Beijing.

[6] Liao, F. (2010) The Study on Excellent Strains of Aroma Enhancement Microorganisms in Tobacco and Fragrance-Induced Technology. Fujian Agriculture and Fore- 
stry University, Fuzhou.

[7] Di Giacomo, M., Paolino, M., Silvestro, D., et al. (2007) Microbial Community Structure and Dynamics of Dark Fire-Cured Tobacco Fermentation. Applied and Environmental Microbiology, 73, 825-837. https://doi.org/10.1128/AEM.02378-06

[8] Wu, X.Y., Liang, S.L. and Han, S.Y., et al. (2014) Diversity of Bacteria in Flue-Cured Tobacco in Different Aging Periods and Development Analysis. Guangdong Agricultural Sciences, 41, 28-33, 38.

[9] Li, T.L.L., Zhou, Y.W., Tang, C.Q., et al. (2012) The Isolation and Identification and Property Analysis of Nicotine-Decomposing Microorganisms in Tobacco Fermentation Process. Tobacco Technology, 12, 60-67.

[10] Shan, H.Y., Chen, D.X., Li, J., et al. (2011) Isolation and Identification, Verification and Application of Effectively Decomposing TSNA Strain AS97 on Fermentation Tobacco Surface. Journal of Microorganisms, 51, 1326-1333.

[11] Wang, J.L., Li, M.Y., Ma, Y.K., et al. (2014) The Study on Degradation of Bacterial Enzymic Preparation on Proteinsin Tobacco. Journal of Agricultural Biotechnology, 22, 486-494.

[12] Guan, L., Li, T.L., Chen, Z.T., et al. (2013) Separation of Cellulose Degradation Bacteria in Aging Tobacco and Property Study. Chinese Tobacco Science, 34, 103-107.

[13] Zhao, M.Q. and Li, F.F. (2009) The Application and Prospect of the Technology of Microbe and Enzyme during Tobacco Leaf Fermentation. Chinese Agricultural Science Bulletin, 1, 314-317.

[14] Zhao, M.Q., Liu, Y., Li, F.F., et al. (2009) The Screening Identification of Dominant Bacteria in Aging Flue-Cured Tobacco and Aroma Enhancement Effect. Journal of Microorganisms, 49, 624-630.

[15] Zhao, M.Q., Wang, B.X., Qiu, L.Y., et al. (2006) Enzymatic Activity and Relevant Chemical Composition Analysis in Flue-Cured Tobacco in Different Aging Period. Journal of China Agricultural University, 11, 7-10.

[16] Wu, D.Z., Zhou, Y.H., Li, Z.H., et al. (2010) Changes of Several Compound Contents and Relevant Enzyme in Fermentation Process of Redried Strips. Chinese Tobacco Science, 31, 78-81.

[17] Qi, L.F., Song, J.Z., Fan, J.Q., et al. (2003) The Best Fermentation Period of Fujian and Yunnan Flue-Cured Tobacco and Suitable Storage Time. Tobacco Technology, 7, 9-12.

[18] Yan, T.J. (2009) The Quality Changing Tendency of Flue-Cured Tobacco Formula Module in Different Producing-Areas and Fermentation Period Study. Henan Agricultural University, Zhengzhou, 28-30.

[19] Qi, L.F., Zhuo, S.C., Song, J.Z., et al. (2010) The Best Fermentation Period of Different Producing-Area Strips and Suitable Storage Time Study. Anhui Agricultural Sciences, 38, 155-157.

[20] Ren, X. (2014) The Chemical Foundation Study on Color Changes in Tobacco Fermentation Process. Chinese Academy of Agricultural Sciences, Beijing.

[21] Hu, Y.C., Yang, S.Y., Li, Y.Q., et al. (2004) Physicochemical Index Changes of Henan Redried Strips B2F and C3F in Aging Process. Tobacco Technology, 5, 11-15.

[22] Wang, X.H., Zhao, Y.C., Li, Y.Q., et al. (2004) Physicochemical Index Changes of Yunnan Redried Strips B2F and C3F in Aging Process. Tobacco Technology, 10, 18-20.

[23] Chen, Y., Yang, J.M., Wang, Y.P., et al. (2016) Influences of Different Warehouse Environments on Relevant Moisture of Strips and Ph Value. Journal of Light Indus- 
try, 31, 45-53.

[24] Yan, K.Y., Gong, Z.L. and Zhang, Y. (2007) The Comparative Analysis of Dried Tobacco pH Value. Tobacco Technology, 6, 49-52.

[25] Gong, X.W., Duan, Y.Q., Huang, J.W., et al. (2010) The Relevant Study on Main Chemical Compositions and Tobacco Grade and Fermentation Time of Tobacco. Journal of Jiangxi Agricultural University, 32, 31-34, 50.

[26] Chen, Y., Yang, J.M., Wang, Y.P., et al. (2017) Influences of Different Warehouse Environment on Soluble Sugar and Alkaloid Content. Journal of Southwest Agriculture, 30, 1020-1026.

[27] Fan, J.Q., Song, J.Z., Chen, W.Z., et al. (2003) Changes of Tobacco Chemical Compositions in Dried Strips in Fermentation Process. Tobacco Technology, 8, 19-22.

[28] Zhu, D.H., Han, J.F., Zhang, A.P., et al. (1999) The Comparative Study on Influences of Natural Fermentation and Artificial Fermentation on Chemical Composition Changes in Flue-Cured Tobacco. Tobacco Technology, 1, 3-5.

[29] Li, Y.Q., Hu, Y.C., Song, Y.L., et al. (2004) The Changing Study on Volatile and Semi-Volatile VFA and $\mathrm{pH}$ Changing Study on Aging Process of Flue-Cured Tobacco. Spice, Essence and Makeup, 3, 21-24.

[30] Guo, W.M., Yin, Q.S. and Song, J.Z. (2008) The Research Progress on Tobacco Chromoplast Pigment and Degradation Product. Journal of NC Agriculture, 23, 358-362.

[31] Zhao, M.Q., Wang, F.F., Zhang, Z.F., et al. (2009) Influences of Different Organic Substances on Chromoplast Pigment and Degradation Products in Flue-Cured Tobacco. Journal of NC Agriculture, 24, 149-152.

[32] Zhang, Q.M., Zhang, Y. and Lin, J.Q. (2014) Chromoplast Pigment and Chemical Composition Changes in Short-Term Fermentation Process of Flue-Cured Tobacco in Different Varieties. Chinese Tobacco Science, 35, 55-58.

[33] Srivastava, R.P. and Chaudary, N. (1990) Quantitative Changes in the Polyphenolic Constituents of Dixie Shade Wrapper Tobacco from Harvesting to Ageing. Tobacco Research, 16, 99-102.

[34] Zhou, H., Shao, H.F., Xu, Z.C., et al. (2009) The Relationship between Redried Strips' Chemical Compositions and Sensory Quality in Different Fermentation Stages. Journal of Sichuan Agricultural University, 27, 433-439.

[35] Zhang, C.Y., Peng, Q.R., Yang, M., et al. (2014) Influences of Natural Fermentation on Guizhou Mountainous Region Tobacco Quality. Farming and Cultivation, 2, 27.

[36] Song, J.Z., Zhang, Z.J., Cheng, Y.L., et al. (2003) Influences of Storage Influences on Fermentation Quality of Flue-Cured Tobacco. Tobacco Technology, 9, 6-8.

[37] Layten Davis, D. and Nielsen, M.T. (2003) Tobacco-Production, Chemistry and Technology. Chemical Industry Press, Beijing.

[38] Yan, K.Y. and Zhao, M.Q. (2008) Tobacco Raw Material Science. Science Press, Beijing.

[39] Chen, W. and Liang, M.K. (2017) Comparison of Different Ventilation Drying System on Applicability of Tobacco Fermentation. Mechanical Manufacturing and Automation, 46, 225-228.

[40] Zeng, W.L. and Liang, P. (2017) Realization of Tobacco Fermentation Warehouse Temperature and Humidity Control System. Light Industry Technology, 33, 97-98, 100.

[41] Li, S.M. (2017) The Quality Management Study on Tobacco Fermentation Warehouse Engineering Construction. Mechanical and Electrical Information, 3, 85-87. 
[42] Zhao, F.C. and Li, W.W. (2017) The Application of New-Type Rotary Dehumidifier in Tobacco Fermentation Warehouse. Light Industry Technology, 33, 94-95.

[43] Liang, M.K., Liu, W. and Xiao, J. (2016) The Applicability of Condensation Heat Recovery Type Pump Temperature Regulation Dehumidification Unit in Tobacco Fermentation. Machine Manufacturing and Automation, 45, 204-207.

[44] Li, Y.J., Guo, Z.C., Hong, H., et al. (2015) The Application of Independent Temperature and Humidity Control Air-Conditioning System in Tobacco Fermentation Warehouse. Safety, 36, 10-14.

[45] Zhang, Y., Jin, Z.X. and Zhang, Y.J. (2014) Optimization of Tobacco Fermentation Warehouse Floor System. Technology Notification, 30, 181-183.

[46] Lin, Y., Xu, Y.G. and Xu, G.H. (2014) The Application of Box Storage Strip RFID System in Fermentation Warehouse Management-Based on Longyan Tobacco Industry Co., Ltd. Logistics Technology, 8, 26-29.

[47] Wang, G., Zhang, C.M. and Wang, H.Q. (2013) The Optimal Design of Tobacco Fermentation Warehouse Phosphine Absorption System and Air-Conditioning System. Tobacco Technology, 2, 16-19, 23.

[48] Chen, M.Y. and Ling, Y.Z. (2011) The Tobacco Fermentation Warehouse Distribution Temperature and Humidity Measurement System Design Based on ZigbBee Communication Technology. Journal of Anhui Engineering University, 26, 23-26.

[49] Ming, W.H., Zhang, H.S., Shi, Z.N., et al. (2015) The New-Type Strips Solar Fermentation Warehouse System. CN204837978U.

[50] Wang, G., Zhang, C.M. and Wang, H.Q. (2013) The Tobacco Fermentation Phosphine Absorption System and Air-Conditioning System of Optimization Design. Tobacco Technology, 2, 16-23.

[51] Liang, W., Sun, J.S., Jin, Y.B., et al. (2013) The Approach to Improve Tobacco Fermentation Quality. Tianjin Agriculture Technology, 19, 57-59.

[52] Li, C.K. (2008) The Microorganism Changes and Application Study on Flue-Cured Tobacco in Natural Fermentation Process. Chinese Academy of Agricultural Sciences, Beijing.

[53] Zhang, T.J., Wang, H.Y., Ren, Y.P., et al. (2010) Influences of Different Packaging on Flue-Cured Tobacco Fermentation Quality. Jiangsu Agriculture Science, 6, 466-468.

[54] Zhang, J.L., Yang, M.F. and Guan, S.S. (2013) Influences of Adding Enzymic Preparation on Flue-Cured Tobacco in Strips Fermentation Process. Modern Agriculture Technology, 13, 215-217.

[55] Sun, J.F. (2013) Influences of Different Fermentation Methods and Storage Conditions on Strips Fermentation. Anhui Agriculture Science, 41, 11491-11493.

[56] Zeng, X.Y., Yang, J.K. and Duan, Y.Q. (2009) Bio-Enzyme of Tobacco and Correlation between Grade and Fermentation Time. Tobacco Technology, 262, 48-51.

[57] Sun, J.G., Yan, T.J., Shi, H., et al. (2008) The Role of Enzyme in Flue-Cured Fermentation Process and Research Progress on Change Characteristics. Hubei Agriculture Science, 10, 1207-1211.

[58] Huang, S., Zhou, J.K. and Wang, Z.X. (2016) Influences of Different Nitrogen Concentration Storage on Main Chemical Compositions on Fermentation Strips. Scientific Research, 10, 54-57.

[59] Zhou, J.K., Wang, Z.X., Sun, H., et al. (2017) Influences of Different Nitrogen Concentration Storage on Sensory Quality of Strips. Industry, 3, 70-72.

[60] Fan, J.Q., Song, J.Z., Lai, C.L., et al. (2005) The Test of Darkening Tobacco Re- 
strained by Oxygen Reduction in Fermentation Process in Sealing. Tobacco Technology, 221, 26.

[61] Liu, J. (2016) Influences of Low-Emission Mechanical Regulation Control Method on Strip Cultivation Fermentation. Hubei Agriculture Science, 55, 1739-1743.

[62] Liu, H.G., Hu, L., Yan, K.L., et al. (2016) Influence Study of Oxygen Content on Fermentation Quality of Redried Strips. Journal of Yunnan Agricultural University (Natural Science), 31, 867-873.

[63] Xia, B.L. and Yan, C.L. (2007) The Tobacco Fermentation Quality Improved by Bio-Enzyme. Tobacco Technology, 49, 7-13.

[64] Zhu, D.L., Xie, J.Q., Hu, W.Y., et al. (2013) Fragrance Fungus Separation Metabolism and Application in Tobacco Fermentation. Food Industry, 3, 154-159.

[65] Huang, L.B., Zeng, J.W., Wu, R.X., et al. (2017) Influences of Atmosphere Regulation Cultivation on Strips Fermentation Quality. Anhui Agriculture Science, 45, 86-89.

[66] Zhuo, S.C. (2010) Mould Proof Insecticide and Fermentation Effect of Different Oxygen Concentrations for Tobacco Dispensing. Anhui Agriculture Science, 38, 158-160.

[67] Yang, X.L. (2017) Influences of Strips Exhaust Gas Storage Technology on Tobacco Fermentation Quality (English). Agricultural Science \& Technology, 12.

[68] Yang, X.L., Yang, Y.F., Zhang, J.L., et al. (2017) Influences of Controlled Atmosphere Storage Technology on Strips Fermentation Quality. Henan Agriculture Science, 46, 153-159.

[69] Yang, B. and Li, L. (2016) Analysis of Suitable Fermentation Time for Tobacco. Modern Agriculture Technology, No. 14, 29-30, 35.

[70] Xu, H., Qi, B., Sun, T., et al. (2012) Variable Selection in Visible and Near-Infrared Spectra: Application to On-Line Determination of Sugar Content in Pears. Journal of Food Engineering, 109, 142-147. https://doi.org/10.1016/j.jfoodeng.2011.09.022

[71] ElMasry, G., Sun, D.-W. and Allen, P. (2012) Near-Infrared Hyperspectral Imaging for Predicting Colour, $\mathrm{pH}$ and Tenderness of Fresh Beef. Journal of Food Engineering, 110, 127-140. https://doi.org/10.1016/j.jfoodeng.2011.11.028

[72] Zhou, L.J., Wu, H., Li, J.T., et al. (2012) Determination of Fatty Acids in Broiler Breast Meat by Near-Infrared Reflectance Spectroscopy. Meat Science, 90, 658-664. https://doi.org/10.1016/j.meatsci.2011.10.010

[73] Tan, C., Wu, T., Xu, Z., et al. (2013) Determination of Total Sugar in Tobacco by Near-Infrared Spectroscopy and Wavelet Transformation-Based Calibration. Analytical Letters, 46, 171-183. https://doi.org/10.1080/00032719.2012.704538

[74] Wu, L., Wang, B.X., Yin, Y.F., et al. (2016) Characterization of Tobacco with Near-Infrared Spectroscopy with Competitive Adaptive Reweighted Sampling and Partial Least Squares Discrimination. Analytical Letters, 49, 2290-2300. https://doi.org/10.1080/00032719.2016.1144763

[75] Liu, N., Peng, Q.R., Yang, M., et al. (2014) The Research Study on Tobacco NIR Model Construction Method. Guizhou Agriculture Science, 42, 85-90.

[76] Zhang, C.H., Hu, Y., Liu, N., et al. (2018) NIR Flue-Cured Tobacco's Producing Area Judgment Based on PCA and Neural Network. Guizhou Agriculture Science, 46, 109-112.

[77] Hu, X.Y. (2013) Application of Visible/Near-Infrared Spectra in Modeling of Soil Total Phosphorus. Pedosphere, 23, 417-421.

https://doi.org/10.1016/S1002-0160(13)60034-X 
[78] Naseer, N., Hong, M.J. and Hong, K.-S. (2014) Online Binary Decision Decoding Using Functional Near-Infrared Spectroscopy for the Development of Brain-Computer Interface. Experimental Brain Research, 232, 555-564.

https://doi.org/10.1007/s00221-013-3764-1

[79] Said, M.M., Gibbons, S., Moffat, A.C., et al. (2014) Rapid Detection of Sildenafil Analogue in Eurycomalongifolia Products Using a New Two-Tier Procedure of the Near Infrared (NIR) Spectra Database. Food Chemistry, 158, 296-301. https://doi.org/10.1016/j.foodchem.2014.02.125

[80] Durantin, G., Gagnon, J.F., Tremblay, S., et al. (2014) Using near Infrared Spectroscopy and Heart Rate Variability to Detect Mental Overload. Behavioural Brain Research, 259, 16-23. https://doi.org/10.1016/j.bbr.2013.10.042 